\title{
School teachers' technology readiness - An empirical study applying readiness factors and teacher type categorization
}

\author{
Badri, M. ${ }^{1}$ Al Rashedi, A. ${ }^{2}$ Mohaidat, J. ${ }^{3}$ \\ ${ }^{1,2,3}$ Abu Dhabi Education Council, Office of Research, and Strategic Affairs
}

\begin{abstract}
The Technology Readiness Index (TRI) was adapted to measure public school teachers' technology readiness in Abu Dhabi, United Arab Emirates. Abu Dhabi teachers are categorized into five main groups, with the highest percentages being either "laggards" or "explorers." This study's findings suggest that the TRI could be a cross-culturally valid measurement scale for Abu Dhabi teachers.
\end{abstract}

\section{Introduction}

To obtain the potential benefits of ICT, school teachers must be receptive to the integration of new technologies into their teaching practice environments. Summak et al. (2010) [1] developed a list summary of such challenges. Many believe that the success of technology integration and its effective use in education depends primarily on teachers' attitudes toward technology and willingness to adopt it $[1,2$, 3]. Parasuraman (2000) [4] developed the Technology Readiness Index (TRI) to measure consumers' continuing willingness to embrace new technologies. He introduces four constructs of technology belief that affect an individual's level of techno-readiness: optimism, innovativeness, discomfort, and insecurity. People can be categorized into distinct groups related to their patterns of scores on the four constructs. Based on cluster analyses of TRI scores on the four constructs,
Parasuraman and Colby (2001) [5] have identified five distinct customer segments (in decreasing order of adoption propensity): explorers (lead users most likely to adopt and experiment with new technologies), pioneers, skeptics, paranoids, and laggards. Teachers' positive attitude facilitates their use of more instructional technology tools to make learning more interesting and attractive for their students [6]. Teachers with negative attitudes towards technology are not expected to benefit in this field nor to efficiently insert technology into the education environment [7]. Effectively categorizing and training teachers on the basis of their TRI profiles could improve ADEC's returns on its ICT investments in the schools by maximizing the effectiveness of teacher professional development programs. The results could help ADEC decision makers design the best means of integrating technology into teacher preparation and preparing teachers to integrate it in their classrooms. It could also support the efficient and effective utilization of school resources.

\section{Methods}

A total of 796 teachers responded to the survey $(42.1 \%$ male and $57.9 \%$ female; with average age of 37.6 years; where $78.2 \%$ of the teachers had bachelor's degrees; with experience ranged from 1 to 40 years; KG $15.49 \%$, Cycle I $32.9 \%$, Cycle II $35.2 \%$, and Cycle III 16.4\%). The study used the 36 -item TRI [4]. The 
Cronbach reliability alphas for the four constructs of technology belief were 0.812 for optimism statements, 0.559 for innovative statements, 0.703 for insecure statements, and 0.720 for discomfort statements. We used the categorization suggested by Parasuraman and Colby (2001) [5] to determine the percent of respondents falling within each of the five categories through cluster analysis. Cluster analysis was used to categorize the responding teachers into the five profiles-explorers, pioneers, skeptics, paranoids, and laggards--suggested by Colby and Parasuraman (2001) [5].

\section{Results}

We performed confirmatory factor analysis to test the factor structure of the modified TRI (the TRI with one innovativeness element removed). However, obtaining an acceptable CFA model required adding a total of 12 correlated error covariance paths between the variables. The LISREL 8.83 solution provides an adequate fit with (Chi-square of 1381.86, with 569 degrees of freedom, RMSEA of 0.04 , GFI of 0.95, and NFI of 0.94). As a result of the CFA, we decided to perform the t-test and ANOVA test without splitting any TRI constructs.

Table 1 presents the mean scores and standard deviations of each TRI construct. Optimism was rated with the highest mean score, 4.1528. The next highestrated construct was innovativeness (3.6116); thus, teachers' optimism level was higher than their innovativeness. These were drivers of TRI (the contributor dimension), reflecting the assumption that the optimism and innovativeness constructs positively affect TRI. The insecurity and discomfort constructs, inhibitors of TRI, yielded mean values of 3.5778 and 2.9647, respectively. The mean of all TRI constructs was 3.2822 with a mean standard deviation of
0.583.The ranking of the means of the TRI constructs is consistent with those of other studies conducted in the education environment [1]. Table 1 also displays the correlation coefficients. All correlation coefficients are significant at the 0.05 level. The correlation analysis revealed high correlations between optimism and innovativeness (0.638), and between insecurity and discomfort (0.595).

Following Lee et al.'s (2009) [8] method, this study used the TRI to provide insight into a person's motivations and inhibitions regarding the technology adoption. When we subtract the discomfort and insecurity item scores from the optimism and innovativeness item scores, we obtain a clearer sense of the proportion of the sample population that is technology ready or non-ready. Results show that $64.9 \%$ are technology ready, and $35.1 \%$ are non-technology ready.

When we ran K-means (the simplest procedure), the data did not cluster very well. When four percentile variables are created using the rank command, and then clustered again, it worked very well. On the basis of the TRI, and using the clusters obtained, the responding teachers were categorized into five profiles: explorers, pioneers, skeptics, paranoids, and laggards. For Abu Dhabi teachers, explorers constitute $21.48 \%$ of the sample. They are the most techno-ready of all categories, with strong motivations to adopt technology and few inhibitions. Demographically, they are more affluent, younger, and more likely to be male. Parasuraman and Colby (2001) [5] asserted that newly introduced technology easily attracts explorers, and they will comprise the first wave of customers. Pioneers constitute $15.45 \%$ of the sample teachers. This category is highly motivated to adopt technology but also inhibited by a high level of insecurity and discomfort. They are the most ethnically diverse category in our sample. ADEC faces the 
challenge of helping them overcome their inhibitions to using technology through support, encouragement, training, friendly design, and reassurance. This category of teachers desires the benefits of the new technology in the classroom but was more practical about the difficulties and obstacles involved. Teacher pioneers need help in making the technology work for them and require some degree of assurance, and were usually the second group to try new technology. Skeptics constitute $22.49 \%$ of the sample. This group of teachers is not too far behind the pioneers; however, these teachers report fewer motivations but also few inhibitions to adopt technologies in the classroom. This group did initially resist technology, but once they were convinced of the benefits of the technology, adoption came readily because there were few reasons to hold back. ADEC should apply this understanding of such teachers to convince them of the underlying benefits of integrating technology in teaching and learning. The paranoid group constitutes $15.45 \%$ of the teacher sample. This group believes in technology's benefits but is constrained by a high level of insecurity and discomfort. Analysis shows that the group tends to be older and has a high percentage of females. They were concerned about the risks, discomfort, and insecurity. The least techno-ready category, laggards constitute $24.45 \%$ of the sample and exhibit little motivation and a high level of resistance to using new technologies in the classroom. Their demographic is much older and more female. Some suggest that this group may never use new technology unless they are forced to do so. ADEC may reach out to them by developing streamlined, easy-touse educational resources and offer mentoring support.

Table 2 reports the percent of each category, and the cross tabulation of the means of the four TRI constructs with the five teacher categories for Abu Dhabi. Further observations reveal that explorers are highly optimistic with a mean of 3.89032 , and innovative with a mean of 3.66333 , with low insecurity and discomfort. The skeptics are low on both optimism and innovativeness. The pioneers exhibit high optimism but also high insecurity. The paranoids report high insecurity but high optimism. Finally, laggards report both high insecurity and discomfort. Table 3 presents a clear profile of each teacher category's levels of the TRI constructs.

\section{Discussions and conclusions}

The findings suggest that each TRI construct has a significantly different influence that can be identified, measured, and analyzed. Abu Dhabi public school teachers' optimism level was higher than their innovativeness, and the mean value of their insecurity construct was higher than that of discomfort. This result is consistent with results obtained by others $[1,9,10]$. For ADEC, the controllability of new technologies is very important to optimistic teachers because convenience is the most frequently stated benefit of using new technologies. Innovativeness received the second highest score. Insecurity and discomfort inhibit TR. Both received the lowest scores. Understanding the teacher's profile (explorers, pioneers, skeptics, paranoids, and laggards) is important. The results provide evidence upon which ADEC strategies targeting each teacher category can be developed to increase the rate of integration of new technologies into the curriculum and pedagogy.

This study's findings suggest specific strategies for the ADEC's technology integration objectives. Overall, the key to bolstering teachers' TRI is the teachers' positive experience with technology. Such experiences lead to more acceptance, 
comfort, and confidence, ultimately nurturing a positive attitude toward its integration into curricula and teaching. For the effective integration of technology, ADEC should educate teachers and advocate for technology's benefits to the teachers and students alike, and thus promote a positive attitude toward technology in the schools' teaching practices. Feedback should be collected for continuous improvement of technology integration.

\section{References}

[1] Summak, M., Baglibel, M., and Samancioglu. (2010). Technology readiness of primary school teachers: A case study in Turkey. Procedia Social and Behavioral Sciences, 2, 2671-2675.
[2] Hew, K. F. and Brush, T. (2007). Integrating technology into K-12 teaching and learning: current knowledge gaps and recommendations for future research. Education Technology Research and Development, 55, 223-252.

[3] Yildirim, S. (2007). Current utilization of ICT in Turkish basic education schools: A review of teacher's ICT use and barriers to integration. International Journal of Instructional Media, 34(2), 171-186.

[4] Parasuraman, A. (2000). Technology Readiness Index (TRI). A multiple-item scale to measure readiness to embrace new technologies. Journal of Service Research, 2(4), 307-320.

[5] Parasuraman, A. and Colby, C.L. (2001). Techno-ready Marketing: How and Why Your Customers Adopt Technology. New York, NY: The Free Press.

Table 1. Means, standard deviations, and correlations

\begin{tabular}{|c|c|c|c|c|c|c|}
\hline Construct & Mean & $\begin{array}{l}\text { Standard } \\
\text { deviation }\end{array}$ & Optimism & Innovativeness & Insecurity & Discomfort \\
\hline Optimism & 4.1528 & .5705 & 1 & & & \\
\hline Innovativeness & 3.6116 & .5561 & $0.638 * *$ & 1 & & \\
\hline Insecurity & 3.5778 & .6672 & $0.122 * *$ & $0.219 * *$ & 1 & \\
\hline Discomfort & 2.9647 & .6085 & 0.019 & 0.020 & $0.595 * *$ & 1 \\
\hline
\end{tabular}

Table 2. Mean distribution of the 4 TRI constructs and 5 teacher categories (profiles)

\begin{tabular}{lcccccc}
\hline & Number & Percent & Optimism & Innovativeness & Insecurity & Discomfort \\
\cline { 2 - 7 } Explorers & 171 & 21.48 & 3.89032 & 3.663330 & 1.090430 & 1.133115 \\
Pioneers & 123 & 15.45 & 3.47002 & 3.022865 & 3.509825 & 1.776845 \\
Skeptics & 179 & 22.49 & 1.66303 & 1.456145 & 1.281300 & 1.858000 \\
Paranoids & 123 & 15.45 & 3.47002 & 3.022865 & 3.509825 & 1.776845 \\
Laggards & 197 & 24.75 & 1.18156 & 1.284595 & 3.417945 & 3.743160 \\
\hline Overall & & & 2.73499 & 2.48996 & 2.561865 & 2.057593
\end{tabular}

Table 3. Characteristics of the 5 categories correlated with the 4 TRI constructs

\begin{tabular}{lcccc}
\hline & Optimism & Innovativeness & Insecurity & Discomfort \\
\cline { 2 - 5 } Explorers & High & High & Low & Low \\
Pioneers & High & High & High & Low \\
Skeptics & Low & Low & Low & Low \\
Paranoids & High & High & High & Low \\
Laggards & Low & Low & High & High \\
\hline
\end{tabular}

